\title{
A DEFINIÇÃO TRIPARTIDA DO CONHECIMENTO E A CRÍTICA DE GETTIER
}

\section{THE TRIPARTITE DEFINITION OF KNOWLEDGE AND GETTIER'S CRITIQUE}

\author{
Lucas Jairo Cervantes Bispo \\ (ljcbispo@outlook.com)
}

\begin{abstract}
RESUMO
O presente texto tem como objeto a definição tripartida do conhecimento como crença verdadeira justificada, tal como apresentada no Teeteto de Platão e hegemonicamente entendida pela epistemologia analítica contemporânea, e a crítica a ela por Edmund Gettier em seu artigo "É a crença verdadeira justificada conhecimento?". A pretensão é expor reflexivamente considerações introdutórias fundamentais acerca de ambas. Para isso, primeiro distinguir-se-ão três tipos de conhecimento, destacando-se o proposicional como aquele em jogo na definição tripartida e na crítica de Gettier; em segundo lugar, apresentar-se-á a estrutura da definição tripartida, suas partes, a relação entre elas, com as intuições pré-teóricas presentes nas mesmas e com o que excluem; por fim, explicar-se-á a crítica de Gettier, evidenciando-se seus pressupostos, estrutura, razões e finalidades.
\end{abstract}

PALAVRAS-CHAVE: Tipos de Conhecimento. Definição. Tripartida. Crítica de Gettier.

\begin{abstract}
The present text has as its object the tripartite definition of knowledge as justified true belief, as presented in Plato's Theaetetus and hegemonically understood by contemporary analytic epistemology, and its criticism by Edmund Gettier in his article "Is justified true belief knowledge?". The goal is to reflexively expose fundamental introductory considerations about both. In order to do this, first we will distinguish three types of knowledge, highlighting the propositional as the one present in the tripartite definition and in Gettier's criticism; secondly, we will expose the structure of the tripartite definition, its parts, the relationship between them, the pre-theoretical intuitions present in them and what they exclude; finally, we will present Gettier's critique, highlighting its assumptions, structure, reasons and purposes.
\end{abstract}

KEYWORDS: Types of Knowledge. The tripartite definition. Gettier's critique.

\section{INTRODUÇÃO}

\footnotetext{
${ }^{1}$ Graduando em Filosofia pela Universidade Estadual de Feira de Santana (UEFS).

CV Lattes: http://lattes.cnpq.br/9051296075210643.

ORCID: https://orcid.org/0000-0001-5572-619X.
} 
O que é conhecimento? O que quer dizer alguém saber alguma coisa? Qual é a diferença entre conhecer ou não algo? Mais específica e analiticamente, qual é o conjunto de condições individualmente necessárias e conjuntamente suficientes para a análise e aplicação correta e completa do conceito de conhecimento e que determinam se alguém sabe alguma coisa?

A preocupação com o conhecimento e sua natureza está presente na história da filosofia, de maneira direta ou indireta, sistematizada ou não, no mínimo desde Platão. Atualmente, como objeto da epistemologia ou da teoria do conhecimento, trata-se de uma das questões mais enigmáticas, persistentes e definidoras desse campo e da filosofia, relacionando-se com ou mesmo sendo fundamentadora para outras áreas filosóficas e também para as ciências.

Tendo isso em vista, o presente texto se debruçará sobre uma definição clássica de conhecimento e uma crítica recente feita a mesma, que se tornou também clássica e que gerou e gera um imenso e controverso debate na discussão filosófica em diversas partes do mundo. Trata-se da definição tripartida do conhecimento como crença verdadeira justificada, tal como apresentada no Teeteto de Platão e como é hegemonicamente entendida pela epistemologia analítica contemporânea, e a crítica a ela por Edmund Gettier em seu artigo "É a crença verdadeira justificada conhecimento?”. A pretensão é expor reflexivamente considerações introdutórias fundamentais acerca de ambas. Para isso, na seção 2 distinguir-se-ão três tipos de conhecimento, destacando-se o proposicional como aquele em jogo na definição tripartida e na crítica de Gettier; na seção 3, apresentar-se-á a estrutura da definição tripartida, suas partes, a relação entre elas, com as intuições pré-teóricas presentes nas mesmas e com o que excluem; posteriormente, na seção 4, explicar-se-á a crítica de Gettier, evidenciando-se seus pressupostos, estrutura, razões e finalidades; por fim, serão elaboradas as considerações finais.

\section{TIPOS DE CONHECIMENTO}

O tipo de conhecimento ao qual a filosofia tem dado maior atenção e que tem discutido mais exaustivamente é o proposicional, isto é, aquele que se deixa expressar através de enunciados e sentenças declarativas, que descrevem um conteúdo, uma possibilidade, uma representação, enfim, passível dos atributos de verdade ou falsidade. A forma desse tipo de conhecimento poderia ser resumida a "S sabe que p", em que "S" representa o sujeito que conhece e "p", a proposição conhecida.

Para Dutra (2010, p. 10), os exemplos mais óbvios do objeto do conhecimento proposicional, em sua terminologia "estados de coisas", seriam os 
fatos empíricos da experiência comum, mas também os que interessam às ciências. É nesse sentido que se apresentam diversos exemplos do seguinte tipo na literatura aqui utilizada: "Gettier é um filosofo", "Maria Bethânia é uma cantora", "Os cangurus dormem a maior parte do tempo", "Cães são mamíferos", "Feira de Santana fica na Bahia" e assim por diante. De maneira mais geral, Stephen Hetherington ${ }^{2}$ cita que em princípio o conhecimento proposicional é um tipo de conhecimento sobre um fato ou verdade, não importando que tipo de fato ou verdade envolve - por exemplo, " $2+2=4$ ", "O estupro é cruel”, "Existe gravidade".

Assim, o conhecimento proposicional pode ser diferenciado, por exemplo, do conhecimento prático/de habilidade e do por contato/familiaridade. O primeiro se refere ao saber como fazer alguma coisa: ver as horas num relógio, andar de bicicleta, cozinhar um alimento etc. Esse tipo de saber pode pressupor e/ou implicar a posse de conhecimento proposicional, mas não necessariamente. Como exemplifica Dan O'Brien (2013, p. 24), "Para eu saber jogar snooker, tenho de saber que a bola azul vale cinco pontos e que tenho de embolsar uma bola vermelha antes de poder embolsar uma bola de cor"; por outro lado, "Posso desempenhar acções básicas como andar, nadar ou falar sem ter de saber que tenho de fazer movimentos específicos com o meu corpo ou boca para esse efeito". O segundo, por sua vez, como explica Linda Zagzebski (1999, p. 92), é aquele que acontece com ou deriva do contato experiencial direto por parte do sujeito que conhece com a porção da realidade conhecida. Por exemplo: conhecer uma pessoa chamada Roger - ou, mais especificamente, conhecer uma pessoa num sentido não ligado a possuir informações sobre ela, mas de perceber que reajo a tal individuo como se já o tivesse visto -, ou conhecer um ritmo porque já o ouvi, ou um local porque já estive lá. Para Linda Zagzebski (1999, p. 92), esse conhecimento por contato/familiaridade inclui não somente pessoas e coisas, mas também e principalmente nossos próprios estados mentais. No caso deste conhecimento, tal como ocorre com o conhecimento prático/de habilidade, não necessariamente há o pressuposto ou implicação do conhecimento proposicional; por exemplo, no caso do ritmo, podemos tê-lo ouvido sem sabermos como se chama ou termos qualquer crença factual a seu respeito.

É importante notar que, apesar dessa distinção ser intuitiva e comum, e, justamente, a que está em questão neste trabalho, não é indisputável. Giovanni Rolla cita cinco possibilidades diferentes de distinção, quais sejam

\footnotetext{
${ }^{2}$ HETHERINGTON, Stephen. Knowledge. The internet encyclopedia of philosophy. ISSN 21610002, <https://www.iep.utm.edu/knowledg>. Acesso em 25 de novembro de 2019.
} 
Em particular, há quem defenda que todo conhecimento proposicional reduzse, em última análise, ao conhecimento objetual dos componentes mínimos das proposições [...] Por outro lado, há aqueles que dizem que não existe contato direto entre um sujeito e um objeto, mas que todo contato é mediado por conceitos [...] Na medida em que o conhecimento proposicional envolve proposições, que são compostas de conceitos, talvez seja defensável dizer que o conhecimento direto não é essencialmente diferente do conhecimento proposicional. Há também quem defenda que conhecimento prático se reduz ao conhecimento proposicional, ou seja, que saber que várias proposições são verdadeiras sobre determinada atividade [...] é suficiente para saber como fazer tal atividade. Por outro lado, há filósofos que acreditam que todo o conhecimento proposicional é um conhecimento prático, saber fazer algo com a verdade de uma proposição. (ROLLA, 2018, pp. 24-25)

Feitas essas distinções, convém perguntar: por que o tipo de conhecimento a que a filosofia tem dado maior atenção e que tem discutido mais exaustivamente é o proposicional? Uma resposta, como sugere Richard Fumerton (2006, p. 19), consiste na suposição de a filosofia estar preocupada com a verdade; como são as proposições as estruturas linguísticas passíveis da mesma, privilegia-se o conhecimento proposicional. Mas podemos também recordar que tal conhecimento é aquele que engloba uma gama de assuntos - conhecimentos científicos, geográficos, matemáticos, autoconhecimento e conhecimentos acerca de qualquer campo de estudo -, constituindo-se como noção fundamental para a cognição humana e necessária tanto para a especulação teórica quanto para o julgamento prático. ${ }^{3}$ Além disso, e talvez mais fundamentalmente, o que diz Linda Zagzebski (1999, p. 92) em relação ao conhecimento proposicional em comparação ao conhecimento por familiaridade - mas que creio que também pode ser aplicado à relação deste último com o conhecimento prático/de habilidade - é que o primeiro tem sido muito mais exaustivamente discutido do que o segundo por pelo menos duas razões: primeiramente, a proposição seria a forma através da qual o conhecimento é comunicado; assim, o conhecimento proposicional poderia ser transferido de uma pessoa para outra, enquanto o conhecimento por familiaridade não o poderia, ao menos diretamente. Em segundo lugar, há a suposição comum de que a realidade possui uma estrutura proposicional ou, ao menos, de que a proposição é a principal forma pela qual a realidade se torna compreensivel para a mente humana.

Ocorre que dessa primazia do conhecimento proposicional não decorre que há esclarecimento e consenso acerca desse conceito e de quando estamos de sua posse; pelo contrário: há mais discussão e dissenso. Ou seja, apesar do largo consenso quanto à estrutura proposicional 'S sabe que p', permanece a discussão acerca do que é esse saber e de

\footnotetext{
${ }^{3} C f$. BERNECKER; DRETSKE (2005, p. 3) e TRUNCELLITO (2007).
} 
quando um sujeito sabe ou não algo. Sendo assim, mantém-se a questão, agora de forma mais específica: o que significa, em sentido proposicional, conhecer?

\section{A DEFINIÇÃO TRIPARTIDA}

Uma definição contemporaneamente muito discutida e dita como aceita amplamente na história da filosofia ${ }^{4}$ e que satisfaz fortemente intuições pré-teóricas, encontra sua raiz nas obras de Platão, mais especificamente no Teeteto, no qual é dito que a crença verdadeira acompanhada de uma explicação é conhecimento, ao passo que a crença verdadeira não acompanhada de uma explicação é distinta do conhecimento:

Sócrates, fiquei agora a pensar numa coisa que tinha esquecido e que ouvi alguém dizer: que o saber é opinião verdadeira acompanhada de explicação e que a opinião carente de explicação se encontra à margem do saber. E aquilo de que não há explicação não é susceptível de se saber [...], sendo, pelo contrário, cognoscível aquilo de que há explicação. (Theaetetus, 201d)

Esse entendimento é comumente reconhecido como definição tripartida, pois compreende o conhecimento como constituindo Crença Verdadeira Justificada. Assim, somente a satisfação de todas as partes permitiria a aplicação do conceito de conhecimento, estando descartadas, como nos lembra Dutra (2010, p. 19), as crenças que possuímos, mas que são falsas ou que, mesmo sendo verdadeiras, não recebem justificação; o mesmo vale para aquelas proposições que, mesmo sendo verdadeiras e passiveis de justificação, não expressam crenças que possuímos. Além disso, do ponto de vista do conhecimento que requer apenas uma justificativa razoável, nesse caso também não se trata de conhecimento a crença que, mesmo justificada, não é verdadeira. ${ }^{5}$

Nessa perspectiva, podemos dizer que essa é a estrutura da definição tradicional (DT)

(DT) $\mathrm{S}$ sabe que p se e somente se:

I. $\quad \mathrm{S}$ crê que p;

II. pé verdadeira;

\footnotetext{
${ }^{4}$ Para Laurence BonJour (2009, p. 39), por exemplo, é razoável dizer que alguma versão ou outra da concepção tradicional de conhecimento foi tomada como certa, ainda que sem especificação detalhada, por praticamente todos os filósofos seriamente preocupados com o conhecimento desde o tempo de Descartes até meados do século XX.

${ }^{5}$ No caso de uma justificativa absoluta: havendo justificativa, haveria a garantia da verdade da crença; logo, toda crença justificada seria verdadeira.
} 
III. S está justificado em crer que $\mathrm{p}$.

De acordo com Alexandre Meyer Luz, as noções presentes nessa estrutura são as seguintes

1. A expressão 'S sabe que p' é tomada em seu sentido proposicional;

2. ' $S$ ' é um sujeito epistêmico qualquer (ou seja, um sujeito capaz de ter estados mentais aos quais atribuímos o status de "epistêmicos", tais como crer, descrer, suspender o juízo, conhecer etc.);

3. 'p' é uma proposição qualquer;

4. 'S crê que p' nos indica que $\mathrm{p}$ está na mente de $\mathrm{S}$ e que $\mathrm{S}$ está disposto a aceitar que p é verdadeira (mesmo sem possuir boas razões para tal);

5. 'p é verdadeira' afirma simplesmente que p descreve algo que ocorre de algum modo independente de $\mathrm{S}$;

6. 'S está justificado em crer que $\mathrm{p}$ ' nos informa que $\mathrm{S}$ tem - falando de modo provisório - 'boas razões' para crer em $\mathrm{p}$, ou que $\mathrm{S}$ tem 'o direito de crer em p'. (LUZ, 2013, p. 19)

Dessa maneira, a proposta da definição tripartida traz uma lista de condições individualmente necessárias e conjuntamente suficientes para o conhecimento, de forma que um sujeito só conhece uma proposição se a satisfizer. Ao se definir o que é o conhecimento, também se exclui aquilo que ele não é e. Como nos lembra Michael Williams (2001, p. 16-17), entre os(as) filósofos(as), desde Platão até hoje, tem havido mais ou menos um completo consenso de que o conhecimento exclui três coisas: a ignorância, o erro e a mera opinião. A condição da crença exclui a ignorância, a da verdade, o erro e a da justificação, a opinião.

Assim, a definição tripartida se constitui não somente como muito antiga ou dita como aceita amplamente na história da filosofia, mas, segundo Linda Zagzebski (2017, p. 188), satisfaz em grande medida diferentes virtudes que uma definição do conhecimento precisaria possuir, como precisão, simplicidade, concisão, elegância, iluminação teórica e utilidade prática. Ademais, como já foi dito, veremos, que se trata de uma concepção que pode satisfazer nossas intuições pré-teóricas. ${ }^{6}$ Com isso em mente, vejamos com mais detalhes e com exemplos o que é cada condição, a relação entre elas e com o que excluem.

A crença é um conceito fundamental à epistemologia. Na perspectiva aqui trabalhada, é a ela que se aplicam os conceitos de verdade, falsidade e justificação. De fato, não só o

\footnotetext{
${ }^{6}$ O que está em jogo aqui é o que nos diz Alexandre Meyer Luz (2006, p. 38): “A suposição é, pois, a de que podemos imaginar certos padrões universais ligados a conceitos (assim como supomos que existem padrões universais de raciocínio, explicitados pela Lógica e pela Matemática). Esta é uma tese que deve ser, ela mesma, tomada com algum cuidado, como nós mesmos sugerimos acima. Tais padrões universais, manifestos através das intuições pré-teóricas, devem ser tomados de forma modesta e devem ser constantemente reavaliados, a fim de eliminar aquilo que é meramente um dado cultural tomado inadequadamente como algo universal".
} 
conhecimento incluiria a crença, como seria ele mesmo um tipo de crença. Fundamentalmente, o que está em jogo na presença da crença para o conhecimento é que não seria possível sabermos que isso ou aquilo é o caso ou não sem acreditarmos nisso - ou seja, só seria possível saber aquilo em que se acredita, que se aceita, de que se está convicto e/ou convencido. ${ }^{7}$ Por consequência, ainda que determinada proposição seja verdadeira - como a ciência diz ser a ideia de a Terra ser esférica e não plana -, se um sujeito não acredita nela, seja porque sequer já a concebeu ou entrou em contato com ela ou porque a nega em sua verdade, não pode conhecê-la. Em outras palavras, se temos conhecimento de que a Terra é esférica, pressupõe-se e se implica que acreditamos nisso; por outro lado, se não acreditamos na esfericidade da Terra, não temos conhecimento de que assim seja. Disso retiram-se também duas alternativas à crença que aparentemente são impossibilitadoras do conhecimento e que reforçam esse caráter necessário da crença para ele: a descrença (negação ou ausência de crença) e a suspensão de juízo (abstenção da decisão entre a crença e a descrença para uma proposição em questão).

Para Linda Zagzebski (1999, p. 93), caracterizar a relação entre um sujeito que conhece e a proposição conhecida como o ato de aquele tomar esta como verdadeira, e isso ser uma relação de crença, é um meio geral bastante difundido. Em sua visão, a ideia de que o estado de conhecimento é uma espécie de crença sustenta a prática quase universal na epistemologia de definir o conhecimento tal como nesse texto está sendo trabalhado.

Não obstante, ainda que a crença seja necessária, ela não é suficiente. Como já foi dito, é preciso que a mesma seja verdadeira. Quanto à verdade (ainda que ela seja um conceito controverso), hegemonicamente ${ }^{8}$, por um lado, considera-se que o que não é verdadeiro não pode ser conhecimento e, por outro, que esse conceito é objetivo, isto é, que uma crença em uma proposição é verdadeira apenas se o conteúdo dessa proposição for o caso, se as coisas se passarem realmente como se acredita. ${ }^{9}$ Trata-se, portanto, da verdade como correspondência, o que nos remete a Aristóteles e ao entendimento de que negar aquilo que é e afirmar aquilo que

\footnotetext{
${ }^{7}$ Cf. DANCY; SOSA; STEUP (2010, p. 259, 476).

${ }^{8} C f$. AUDI (2003 p. 220), STEUP; ICHIKAWA (2017), ou ainda BERNECKER; PRITCHARD (2011, p. 3).

${ }^{9}$ Note-se que, assim como Truncellito (2007), estou assumindo a existência de uma verdade objetiva, o que torna possível que as crenças correspondam ou não à realidade. Assim, para que alguém saiba alguma coisa deve haver algo possível de conhecimento. Lembremo-nos de que estamos discutindo conhecimento em sentido proposicional e factivo; se não há fatos, então não há nada a saber. Obviamente, essa suposição não é universalmente compartilhada e sua defesa não faz parte do escopo deste trabalho; contudo, posso dizer que, se verdade é uma condição do conhecimento - de modo que, se uma crença não é verdadeira, não pode constituir conhecimento - e se, por conseguinte, não há verdade, então não pode haver conhecimento. Por isso, mesmo que existam verdades, se existe um domínio em que não há verdade, então não poderia haver nele conhecimento.
} 
não é é falso, enquanto afirmar o que é e negar o que não é é verdadeiro. ${ }^{10}$ É nesse sentido que Linda Zagzebski (1999, p. 93) diz que, apesar de as proposições poderem ser verdadeiras ou falsas, apenas proposições verdadeiras ligam o sujeito que conhece à realidade conhecida. Por isso, afirma, o objeto de conhecimento no sentido de maior interesse para os filósofos é geralmente uma proposição verdadeira.

Podemos, portanto, exemplificar que, se Fernando Haddad não ganhou as eleições presidenciais de 2019 no Brasil, ninguém pode saber que ele ganhou, pois se trata de uma proposição falsa; ou, se perguntamos as horas para alguém e se esse alguém olha seu relógio, nos diz e acreditamos, mas seu relógio está desregulado e mostra a hora errada, teremos uma crença falsa e não nos será possível ter conhecimento de que o horário é aquele, porque não é. O próprio modo como utilizamos a linguagem, nota Robert Audi, mostraria que pressupomos que o conhecimento envolve a crença verdadeira

\begin{abstract}
All we claim we know something and later discover that it is false, we sometimes say things like 'Well, I certainly believed it'; but we do not seriously maintain that we knew it. One might say 'I just knew it', but this is usually taken to exhibit an inverted commas use of 'know,' a use in which 'know' stands in for something like 'was certain'. If we seriously insisted we knew it, others would likely conclude that (for instance) we do not really believe that it is false, or perhaps that we are unaware that we are using 'I knew' to mean 'I felt great confidence', as in 'I just knew I'd win - I still can't really believe I lost'. In cases like the commonsense ones just described, when truth is subtracted from what appears to be knowledge, what remains is not knowledge but belief. (AUDI, 2003, p. 220-221) ${ }^{11} 12$
\end{abstract}

\footnotetext{
${ }^{10}$ Digo isso considerando a ressalva de Steup e Ichikawa (2017), quando alegam que a verdade de algo não exige que alguém possa saber ou provar que é verdade, e que nem todas as verdades são verdades estabelecidas. Eles exemplificam que, se jogarmos uma moeda para cima e não verificarmos como aterrisou, pode ser que ela tenha caído com cara ou coroa, mesmo que ninguém tenha como dizê-lo. Para eles, a verdade é uma noção metafísica, em oposição a uma noção epistemológica: a verdade tem a ver com como as coisas são, e não com como elas podem ser alcançadas e mostradas. Então, quando se diz que apenas coisas verdadeiras podem ser conhecidas, isso não se refere ainda a como alguém pode acessar a verdade.

11 "Todos nós afirmamos que sabemos algo e depois descobrimos estar errados. Às vezes dizemos coisas como 'Bem, eu certamente acreditei', mas não afirmamos seriamente que sabíamos disso. Pode-se dizer 'Eu sabia', mas isso geralmente é usado para exibir uma utilização não literal de 'saber', um uso em que 'saber' representa algo como 'tinha certeza'. Se insistíssemos seriamente em que sabíamos, outros provavelmente concluiriam que (por exemplo) não acreditamos realmente estar errados, ou talvez que não estamos cientes de que estamos usando 'eu sabia' para dizer 'senti grande confiança', como em 'Eu sabia que ia ganhar - ainda não consigo acreditar que perdi'. Em casos como os de senso comum que acabamos de descrever, quando a verdade é subtraída do que parece ser conhecimento, o que resta não é conhecimento, mas crença." (tradução nossa)

${ }^{12} \mathrm{Na}$ argumentação de Audi, esses pontos sugeririam que o conhecimento é ao menos crença verdadeira. Segundo o autor, se estamos certos de alguma coisa - por exemplo, de que um amigo está com raiva -, podemos dizer não acreditarmos, mas sabermos disso; porém, isso será mais bem compreendido se significando que não apenas acreditamos, mas sabemos. Semelhantemente, pode ser enganoso dizermos que acreditamos que nosso amigo está com raiva se nós sabemos disso, pois
} 
Dentro desse ponto de vista, como argumenta David A. Truncellito (2007), a busca pelo conhecimento significa uma tentativa de aumentar nosso arsenal de crenças verdadeiras e diminuir o de falsas. A seu ver, ainda que possamos formar crenças por razões diversas, como para criar uma atitude positiva, quando visamos ao conhecimento essas crenças teriam o propósito de descrever ou capturar o modo como as coisas realmente são - isto é, quando se forma uma crença, busca-se uma correspondência entre a mente e o mundo. Por que não entendermos, então, que o conhecimento é crença verdadeira? Afinal, se aceitamos uma proposição como verdadeira e ela realmente o é, não a conhecemos?

Para refletirmos introdutoriamente sobre essa questão, consideremos o seguinte exemplo adaptado de Adam Morton (2003, p. 88): um meteorologista, X, prepara-se para fazer um relatório de rádio acerca do tempo previsto para o dia seguinte; no entanto, ele descobre, cinco minutos antes de ir ao ar, que perdeu todos os dados-base do relatório. Sendo assim, decide jogar uma moeda e relatar com base na sorte. Cara para chuva, coroa para tempo seco. Cara para ventos abaixo de certa quantidade de quilômetros, coroa para acima etc. A partir disso, depois de cinco minutos, ele monta um relatório, vai ao ar e prevê um furacão, embora nada naquele dia pareça indicar isso. Nesse exemplo, diz Adam Morton, pensaríamos que X não sabe que haverá um furacão no dia seguinte; mas, se supormos que no dia seguinte, por mais estranho que pareça, um furacão realmente ocorra, $\mathrm{X}$ teria uma crença verdadeira. Isso não transformaria, no entanto, seu relatório em conhecimento; tratou-se apenas de adivinhação, e o acerto foi por acaso.

Esse é um dentre muitos exemplos nos quais um sujeito possui uma crença verdadeira que para a análise tradicional não se constitui como conhecimento. Isso porque, nessa compreensão, uma crença verdadeira pode ser formada de modo epistemologicamente impróprio, sem mérito, com base em crenças falsas, ignorâncias e/ou sorte. Por isso, não basta à crença ser verdadeira, é preciso que seja justificada. ${ }^{13}$ É nesse sentido que Robert Audi argumenta

Does knowing something also imply justifiedly believing it? If it does, that would explain why a true belief based on a lucky guess is not knowledge. If, from a distance, I see Jim walk hurriedly down the hall and simply guess that

poderíamos assim estar sugerindo que não sabemos e até duvidamos de que o esteja, pois apenas acreditamos.

${ }^{13}$ Lembrando que, como destacam Bernecker e Dretske (2005, p. 3), a justificação epistêmica para a crença é uma justificação para a verdade da crença, e não para sua utilidade ou respeitabilidade social. 
he is angry, I am not justified in believing that he is angry. If my belief turns out to be true, it still does not constitute knowledge. That fact seems explainable by its lack of justification. Now suppose I go by his office and see him briskly shuffling papers and angrily mumbling curses. At this point I might come to know that he is angry; and my acquiring knowledge that he is can be explained by my having acquired evidence which justifies my true belief that he is.

Still, could a true belief that is not justified constitute knowledge? Suppose I simply see Jim briskly shuffling papers as I pass his office, but do not hear any curses. A bit later, I see him walk hurriedly down the hall. Given that I know his fiery temperament, I might have just enough evidence so that I have some reason to believe he is angry, even though I am not quite justified in believing this. Might I now have a kind of low-grade knowledge that he is angry? This is doubtful. My evidence for believing this is not firm. But the case does show this much: that as our evidence for a true belief mounts up in a way that brings us closer to justification for holding the view that justified belief is an element in knowledge. (AUDI, 2003, p. 221) (4 $^{14}$

Convém notar, porém, que se aceitamos que uma crença é justificada ainda que sua justificativa não seja absoluta, completamente conclusiva, é possível que ela seja falsa, como mostra o seguinte exemplo

A detective, FitzB, is investigating a murder. Near the victim's body she finds a wallet containing a driver's license in the name of $Z$. She goes to interview $\mathrm{Z}$ and finds that he has left town in a hurry. $\mathrm{Z}$ is tracked down and found to have traces of the victim's blood under his fingernails. Moreover his fingerprints are all over the scene of the crime. A little investigation reveals that $\mathrm{Z}$ has a long-standing grudge against the victim and stood to gain a lot of money from the victim's death. There are no other suspects. FitzB concludes that she has solved the crime: $\mathrm{Z}$ is the killer.

But $Z$ is not the killer. $Z$ was framed by a very clever enemy of the victim who managed to plant all the evidence while leaving no traces of her activities. $Z$ is convicted and executed, and the real killer is never brought to justice. So

\footnotetext{
14 "Saber algo também implica justificadamente acreditar nisso? Se sim, isso explicaria por que uma crença verdadeira baseada em um palpite de sorte não é conhecimento. Se, de longe, vejo Jim caminhar apressadamente pelo corredor e simplesmente adivinho que está com raiva, não tenho justificativa para acreditar que ele está com raiva. Se minha crença se mostrar verdadeira, ainda não constitui conhecimento. Esse fato parece explicável por sua falta de justificativa. Agora, suponha que eu vá ao escritório dele e o veja revirando papéis e resmungando com raiva. Nesse ponto, posso chegar a saber que ele está com raiva, e meu conhecimento adquirido de que ele está pode ser explicado por eu ter adquirido evidências que justificam minha verdadeira crença de que ele assim está.

Ainda assim, poderia uma crença verdadeira que não é justificada constituir conhecimento? Suponha que eu simplesmente veja Jim folheando rapidamente papéis enquanto passo por seu escritório, mas não ouço praguejações. Um pouco depois, vejo-o andar apressadamente pelo corredor. Dado que conheço seu temperamento inflamado, posso ter apenas evidências suficientes para que eu tenha alguma razão para acreditar em que ele está com raiva, mesmo que eu não esteja justificado em acreditar nisso. Será que agora tenho um pequeno grau de conhecimento de que ele está com raiva? Isso é duvidoso. Minha evidência para acreditar nisso não é firme. Mas esse caso mostra que, na medida em que nossa evidência de uma crença verdadeira se eleva de uma forma que nos aproxima da justificação e, portanto, do conhecimento, isso colabora para a visão de que a crença justificada é um elemento do conhecimento." (tradução nossa)
} 
FitzB did not know that $\mathrm{Z}$ was the killer. She thought she knew, and she had very good reasons for so thinking. But in fact her belief was false and so it cannot have been knowledge. (MORTON, 2003, p. 88) (15 $^{15}$

Considerando-se a argumentação anterior, um sujeito pode possuir crença numa proposição, mas esta ser falsa, ou verdadeira, porém injustificada, ou, ainda que justificada, falsa. Em outras palavras, o fato de acreditarmos em algo não nos garante estarmos certos. Se estivermos certos, isso não implica que possuímos uma justificativa, o que dependerá de como a crença foi formada e o que a fundamenta ou não. Mas, mesmo estando razoavelmente justificados, podemos estar errados, ainda que assumamos que crenças justificadas tenham mais legitimidade epistemológica, sejam mais prováveis de serem verdadeiras e estejam mais propensas a ser conhecimento do que crenças injustificadas.

A partir dessa análise, retornamos para a apresentação inicial da definição tripartida do conhecimento, segundo a qual um sujeito só possui conhecimento de uma proposição se são satisfeitas as condições necessárias e suficientes para isso - quais sejam, ter uma crença verdadeira justificada. Acontece que, apesar de tal definição surgir no Teeteto, ela não foi aceita nesse diálogo pelo personagem Sócrates (Theaetetus, 210a, 210b), normalmente porta-voz de Platão em seus textos, e nem pelo interlocutor que propôs a definição, Teeteto. Além disso, contemporaneamente sua aceitação é incomum e controversa. Convém, portanto, que nos perguntemos: não haveria casos nos quais um sujeito satisfaz essas condições, mas não possui conhecimento? Ou que possui conhecimento sem satisfazê-las? A definição tripartida realmente se sustenta e se aplica?

\section{A CRÍTICA DE GETTIER}

Experimentos mentais hipotéticos podem prover casos apropriados de testes das teorias filosóficas, e foi valendo-se dos mesmos que Edmund Gettier, em 1963, num artigo chamado

\footnotetext{
15 "Uma detetive, FitzB, está investigando um assassinato. Perto do corpo da vítima, ela encontra uma carteira contendo uma habilitação de motorista em nome de Z. Ela vai entrevistar Z e descobre que ele saiu da cidade com pressa. $Z$ é rastreado e tem vestígios do sangue da vítima sob as unhas. Além disso, suas impressões digitais estão por toda a cena do crime. Uma pequena investigação revela que $\mathrm{Z}$ tem um ressentimento de longa data contra a vítima e poderia ganhar muito dinheiro com a morte dela. Não há outros suspeitos. FitzB conclui que resolveu o crime: $\mathrm{Z}$ é o assassino. Mas $\mathrm{Z}$ não é o assassino. $\mathrm{Z}$ foi usado por um inimigo muito inteligente da vítima que conseguiu plantar todas as provas, sem deixar rastros de suas atividades. $Z$ é condenado e executado, e o verdadeiro assassino nunca é levado à justiça. Sendo assim, FitzB não sabia que $\mathrm{Z}$ era o assassino. Ela achou que sabia e tinha boas razões para isso. Mas, na verdade, sua crença era falsa e, portanto, não pode ter sido um conhecimento." (tradução nossa)
} 
"É a crença verdadeira justificada conhecimento?", questionou essa concepção tradicional de conhecimento e defendeu que, ainda que a crença, a verdade e a justificação sejam necessárias para o conhecimento, elas não são suficientes. Nesse artigo, sua estratégia consiste basicamente em oferecer dois contraexemplos nos quais julga mostrar que há casos nos quais o sujeito possui crença verdadeira justificada, mas não admitiríamos que tem conhecimento.

No primeiro exemplo, Smith e Jones concorrem a uma vaga de emprego e Smith acredita que a seguinte proposição conjuntiva $A$ é verdadeira: "Jones é o homem que vai conseguir o emprego e Jones tem dez moedas no bolso". Suas razões seriam que o próprio presidente da empresa lhe teria assegurado que Jones seria selecionado, ou seja, teriam como base o testemunho e o fato de que Smith teria contado as moedas no bolso de Jones, quer dizer, teriam como base seus sentidos. Nesse caso, consequentemente, a proposição $A$ implica validamente a seguinte, $B$ : "O homem que vai ficar com o emprego tem dez moedas no bolso", na qual Smith passa a crer. Assim, se Smith percebe que $A$ implica $B$ e aceita $B$ com base em $A$, proposição para a qual tem fortes provas, estaria justificado em acreditar que $B$ é verdadeira.

Gettier nos convida a imaginar então que, sem saber, Smith é que será selecionado e que ele também tem exatas dez moedas no bolso. Desse modo, a proposição $A$, "Jones é o homem que vai conseguir o emprego e Jones tem dez moedas no bolso", torna-se falsa, mas a proposição $B$, "O homem que vai ficar com o emprego tem dez moedas no bolso", permanece verdadeira, o que segundo Gettier nos permitiria dizer que Smith acredita numa proposição verdadeira e, como a inferiu de outra para a qual possuía justificação, também estaria justificado quanto a esta. Ou seja, Smith teria crença verdadeira justificada em relação à proposição $B$.

Em seu segundo exemplo, Smith tem fortes evidências para acreditar na proposição $A$, "Jones tem um carro Ford", porque desde que se lembra Jones sempre teve esse carro e Jones acabara de lhe oferecer carona dirigindo o mesmo. Gettier então nos sugere pensar que Smith tem um amigo de paradeiro desconhecido chamado Brown. Então, da proposição $A$, para a qual possui justificação, infere outras três: $B$, "Ou Jones tem um Ford ou Brown está em Boston"; $C$, “Ou Jones tem um Ford ou Brown está em Barcelona”; $D$, “Ou Jones tem um Ford ou Brown está em Brest-Litovsk". Smith estaria justificado em acreditar na verdade de cada uma dessas porque, explica Dutra (2010, p. 23), trata-se de proposições disjuntivas exclusivas - isto é, que para serem verdadeiras basta que apenas uma das proposições seja verdadeira -, e, como possui justificativa para a verdade da proposição $A$, "Jones tem um carro Ford" e não possui nenhuma razão para pensar que Brown esteja em algum desses locais, possuiria justificativa também para as outras proposições inferidas dessas. 
Ocorre que o carro de Jones é alugado e, por coincidência, Brown está em Barcelona. Assim, ainda que a proposição $A$, "Jones tem um carro Ford", torne-se falsa, a proposição $C$, “Ou Jones tem um Ford ou Brown está em Barcelona”, permanece verdadeira, e, como Smith estava justificado em acreditar na verdade de cada uma daquelas proposições, tem crença verdadeira justificada em $C$.

Em cada um desses exemplos, conclui Gettier, Smith possui crença verdadeira justificada, mas não tem conhecimento, provando-se assim a insuficiência da definição tripartida. Vejamos qual é a estrutura, os pressupostos desses exemplos e as razões dessa conclusão por parte de Gettier.

Quanto à estrutura, considerando-se esses exemplos, Alexandre Meyer Luz esclarece ser a seguinte a dos casos de Gettier ou do mesmo tipo

(G) Em um contra-exemplo de tipo-Gettier, dados $S$ e $p$ :

(1) a condição de verdade é cumprida para com $p$;

(2) a condição de crença é dada em relação a $p$;

(3) a condição de justificação é satisfeita em relação a $p$;

(4) $\mathrm{S}$ tem justificação para e crê em $q$;

(5) A justificação de $p$ para $S$ depende de $q$;

(6) $q$, ou alguma outra crença, $r$, é falsa;

(7) $S$ não sabe que $p$. (LUZ, 2013, p. 36)

Linda Zagzebski (1999, p. 100), por sua vez, vê nessa estrutura um processo de dupla sorte, na qual partimos, por acidente de má-sorte, de crenças falsas justificadas e, devido a outro acidente - este de boa sorte -, a crença se torna verdadeira, de modo que poderíamos construir casos de Gettier utilizando o seguinte procedimento

[...] start with a case of justified (or warranted) false belief. Make the element of justification (warrant) strong enough for knowledge, but make the belief false. The falsity of the belief will not be due to any systematically describable element in the situation, for if it were, such a feature could be used in the analysis of the components of knowledge other than true belief, and then truth would be entailed by other components of knowledge, contrary to the hypothesis. The falsity of the belief is therefore due to some element of luck. Now emend the case by adding another element of luck, only this time an element which makes the belief true after all. The second element must be independent of the element of warrant so that the degree of warrant is unchanged. This situation might be described as one element of luck counteracting another. We now have a case in which the belief is justified (warranted) in a sense strong enough for knowledge, the belief is true, but it is not knowledge. (ZAGZEBSKI, 1994, p.69) ${ }^{16}$

\footnotetext{
16“[...] Comece com um caso de crença falsa justificada (ou garantida). Torne o elemento da justificação (garantia) forte o suficiente para o conhecimento, mas torne a crença falsa. A falsidade da crença não se deve a nenhum elemento sistematicamente descritível na situação, pois, se assim
} 
Em relação aos pressupostos, dois deles são explícitos e revelados pelo próprio Gettier

[...] in that sense of 'justified' in which S's being justified in believing $\mathrm{P}$ is a necessary condition of S's knowing that $\mathrm{P}$, it is possible for a person to be justified in believing a proposition that is in fact false. Secondly, for any proposition $\mathrm{P}$, if $\mathrm{S}$ is justified in believing $\mathrm{P}$, and $\mathrm{P}$ entails $\mathrm{Q}$, and $\mathrm{S}$ deduces $\mathrm{Q}$ from $\mathrm{P}$ and accepts $\mathrm{Q}$ as a result of this deduction, then $\mathrm{S}$ is justified in believing Q. (GETTIER, 1963, p. 121) ${ }^{17}$

Há ainda pelo menos dois outros pressupostos, estes menos explícitos, como alerta Dutra. Para esse comentador, Gettier presume

[...] que há formas inferenciais preservadoras da verdade, como é usual dizer na filosofia e na lógica, e que o conhecimento obtido por inferência é tão legítimo quanto aquele que pode ser obtido por outros meios, por exemplo, diretamente, ao examinarmos pelos sentidos determinado objeto. Em segundo lugar, conta como justificação o testemunho tanto de nossos sentidos quanto aquele fornecido por outros indivíduos. (DUTRA, 2010, p. 21)

Desses pressupostos, os dois explicitados pelo próprio Gettier recebem maior atenção na literatura aqui trabalhada. O primeiro pressupõe e implica o falibilismo. Como elucida Stephen Hetherington

The justification that is present within each case is fallible. Although it provides good support for the truth of the belief in question, that support is not perfect, strictly speaking. This means that the justification leaves open at least the possibility of the belief's being false. The justification indicates strongly that the belief is true - without proving conclusively that it is. (HETHERINGTON, 2005, seção 5, grifo do autor) $^{18}$

\footnotetext{
fosse, esse recurso poderia ser usado na análise de componentes do conhecimento que não sejam a crença verdadeira e, então, a verdade seria implicada por outros componentes do conhecimento, contrariando a hipótese. A falsidade da crença é, portanto, devido a algum elemento da sorte. Agora emende o caso, adicionando outro elemento de sorte, só que desta vez um elemento que torna a crença verdadeira, afinal. O segundo elemento deve ser independente do elemento de garantia, para que o grau de garantia não seja alterado. Essa situação pode ser descrita como um elemento de sorte que neutraliza outro. Agora temos um caso em que a crença é justificada (garantida) em um sentido forte o suficiente para o conhecimento, a crença é verdadeira, mas não há conhecimento. (ZAGZEBSKI, 1994, p.69, tradução própria)

17 “[...] se tomarmos 'justificado' no sentido em que S está justificado em acreditar que P constitui uma condição necessária para que $\mathrm{S}$ saiba que $\mathrm{P}$, então é possível que uma pessoa esteja justificada em acreditar numa proposição que é de fato falsa. Em segundo lugar, para toda proposição $\mathrm{P}$, se $\mathrm{S}$ está justificado em acreditar que $\mathrm{P}$ e $\mathrm{P}$ implica $\mathrm{Q}$ e $\mathrm{S}$ deduz $\mathrm{Q}$ de $\mathrm{P}$ e aceita Q como resultado desta dedução, então S está justificado em acreditar que Q." (GETTIER, 1963, p. 1, trad. Célia Teixeira com revisão de W. J. Silva Filho)

18 "A justificativa presente em cada caso é falível. Embora forneça um bom suporte para a verdade da crença em questão, esse apoio não é perfeito, estritamente falando. Isso significa que a justificativa
} 
O segundo Alexandre Meyer Luz define como Princípio do Fechamento para a Justificação (PFJ) e explica que,

Se $S$ está justificado em crer que $p$ e $S$ percebe que $p$ implica validamente $q$, então $S$ está justificado em crer que $q$. A plausibilidade de (PFJ) parece estar fortemente ligada à ideia de que as regras da lógica são bons transmissores de alguma qualidade. É amplamente aceito que deduções logicamente válidas são boas transmissoras da verdade. Pelas mesmas razões parece ser razoável considerá-las como boas transmissoras da justificação. (LUZ, 2013, p. 21)

São esses princípios que, em minha interpretação, fundamentalmente permitem a Gettier concluir que em seus exemplos existe uma crença não somente verdadeira, mas também justificada. No que se refere às razões de Gettier para afirmar que, apesar de haver crença verdadeira e justificada em seus exemplos, não há conhecimento, pode-se citar, a partir de uma interpretação do que está dito explícita e implicitamente em seu artigo, que tais razões se resumem ao fato de a verdade e a justificativa para a crença final terem dependido de crenças falsas, ignorâncias e sorte.

No primeiro exemplo, Smith acreditou que Jones conseguiria o emprego, sem saber que ele, Smith, é quem conseguiria; além disso, baseou sua crença - de que quem conseguiria o emprego seria o homem com dez moedas no bolso - nas as moedas do bolso de Jones, sem saber que possuía também a mesma quantidade de moedas. Ou seja, a justificativa de Smith para acreditar na verdade de $B$ dependeu de uma crença falsa (Jones conseguirá o emprego), e a verdade de $B$ dependeu de ignorâncias e sortes (o fato de Smith ter dez moedas no bolso e ser quem conseguirá o emprego)

In our example, then, all of the following are true: (i) (e) ${ }^{19}$ is true, (ii) Smith believes that (e) is true, and (iii) Smith is justified in believing that (e) is true. But it is equally clear that Smith does not know that (e) is true; for (e) is true in virtue of the number of coins in Smith's pocket, while Smith does not know how many coins are in Smith's pocket, and bases his belief in (e) on a count of the coins in Jones's pocket, whom he falsely believes to be the man who will get the job. (GETTIER, 1963, p. 122) ${ }^{20}$

\footnotetext{
deixa aberta pelo menos a possibilidade da crença ser falsa. A justificação indica fortemente que a crença é verdadeira - sem provar conclusivamente que é." (tradução nossa)

${ }^{19}$ A proposição "(e)", no escrito original de Gettier, corresponde a "The man who will get the job has ten coins in his pocket".

20 “Assim, no nosso exemplo, as seguintes proposições são verdadeiras: (i) (e) é verdadeira, (ii) Smith acredita que (e) é verdadeira, e (iii) Smith está justificado em acreditar que (e) é verdadeira. Mas é igualmente claro que Smith não sabe que (e) é verdadeira; pois (e) é verdadeira em virtude das moedas que estão no bolso de Smith, ao passo que Smith não sabe quantas moedas tem no bolso e baseia sua crença em (e) no facto de ter contado as moedas do bolso de Jones, que ele erradamente
} 
No segundo exemplo, Smith acreditou na proposição falsa de que Jones possuía um carro Ford sem saber que o carro era alugado, e baseou sua crença de que ou Jones tem um Ford ou Brown estaria em Barcelona na suposta verdade da primeira e crendo ser falsa a segunda, que não sabia ser verdadeira. Ou seja, a justificativa de Smith para acreditar na verdade de $C$ dependeu de uma crença falsa (Jones tem um Ford), e a verdade de $C$ dependeu de ignorâncias e sortes (o fato de Jones não ter um Ford e estar em Barcelona). ${ }^{21}$

Não obstante essa explicação que vincula crenças falsas, ignorâncias e sorte, o que estaria fundamentalmente em jogo em ambos os casos, conforme a interpretação hegemônica, seria uma falta de mérito epistemológico causada pela sorte no alcance da crença verdadeira justificada. É nesse sentido que Linda Zagzebski argumenta que

Gettier's examples are cases in which a belief is true and justified, but it is not an instance of knowledge because it is only by chance that the belief is true. Writers on Gettier normally do not say what they think is wrong with chance, but Aristotle does when he says, "To leave the greatest and noblest of things to chance would hardly be right". Aristotle is here referring to eudaimonia or happiness, but his point is a general one about goods, at least great goods, and knowledge is surely a great good. It is incompatible with the value of knowledge that the aim of the knower, namely, getting the truth, occur by chance. This much has rarely been disputed even though, as we have seen, the sense of good intended has certainly been disputed. (ZAGZEBSKI, 1999, p. $100)^{22}$

Isso nos revela outro pressuposto fundamental da crítica de Gettier, pressuposto esse que, como Duncan Pritchard mostra na introdução de seu Epistemic luck (2005), é aceito na história da filosofia e em especial na epistemologia contemporânea em geral como ponto pacifico, sem discussão ou fundamentação, e que, acrescentemos, pode ser negligenciado ou

\footnotetext{
acredita ser o homem que ficará com o emprego." (GETTIER, 1963, p. 2, trad. Célia Teixeira com revisão de W. J. Silva Filho)

21 Notemos que, se no primeiro exemplo Gettier argumenta por que Smith não possuiria conhecimento, no segundo exemplo Gettier apenas o apresenta. Considerando isso e a estrutura em comum de ambos, a interpretação adotada foi a de que Gettier está pressupondo implicitamente a validade da análise do primeiro para o segundo.

22 "Os exemplos de Gettier são casos em que uma crença é verdadeira e justificada, mas não é uma instância de conhecimento porque é apenas por acaso que a crença é verdadeira. Escritores sobre Gettier normalmente não dizem o que acham errado com a sorte, mas Aristóteles o faz quando diz: "Deixar a maior e mais nobre das coisas ao acaso dificilmente seria correto". Aristóteles está se referindo aqui à eudaimonia ou felicidade, mas seu argumento é geral sobre bens, pelo menos grandes bens, e o conhecimento é certamente um grande bem. É incompatível com o valor do conhecimento que o objetivo do conhecedor, a saber, obter a verdade, ocorra por acaso. Isso raramente tem sido contestado, embora, como vimos, o senso de bem desejado tenha sido certamente contestado." (tradução nossa)
} 
sequer notado na análise dessa crítica: o pressuposto de que o conhecimento é incompatível com a sorte ${ }^{23}$. Nesse sentido, explica Rolla

[..] considere quando dizemos que algo foi sorte: você tem sorte de ganhar na loteria porque as chances de perder são muitas, e se você comprasse um ou outro bilhete teria perdido. Uma pessoa tem sorte de ter sobrevivido a um acidente porque muito facilmente poderia ter morrido. Em geral, a ideia é que um evento é uma questão de sorte se ele ocorre, mas poderia facilmente não ter ocorrido. $\mathrm{O}$ azar funciona de modo semelhante: uma pessoa tem azar se acontece algo negativo que dificilmente teria acontecido, por exemplo, um congestionamento fora de hora que faz com que ela se atrase para a entrevista de emprego e perca a vaga. O que isso nos diz sobre a sorte epistêmica? A ideia é, se uma crença é verdadeira, mas facilmente seria falsa, então ela não é conhecimento. (ROLLA, 2018, p. 59-60)

Tal pressuposto é o conteúdo das intuições sobre o que devemos esperar de casos de conhecimento que, nos termos de Alexandre Meyer Luz (2006, p. 43; 2013, p. 28-29), chocamse com os exemplos de Gettier, estes que, por sua vez, não as satisfazem, não manifestam o que desejamos através do conceito de conhecimento.

Aqui poderíamos dizer que, se por um lado é a presença e aceitação dos pressupostos do falibilismo e do PFJ que fazem dos exemplos de Gettier crenças verdadeiras justificadas, por outro é por eles terem sido formados através da sorte que não têm o mérito epistemológico para o estatuto de conhecimento.

Poderíamos argumentar também que não se trata apenas de sorte, mas de seus exemplos terem dependido de crenças falsas e da utilização equivocada do PFJ (justamente por partir dessas falsidades). Ocorre que é possível um caso do tipo-Gettier, que assim se caracteriza partindo apenas de crenças verdadeiras e sem a utilização do PFJ, mas que depende ainda assim do falibilismo e da incompatibilidade com a sorte enquanto pressupostos e da formação acidental final da crença verdadeira justificada.

Para percebermos isso, consideremos a seguinte argumentação proposta por Richard Feldman (1974, p. 69): imaginemos que Sr. Nogot relate a Smith que possui um Ford e lhe mostre um certificado disso; suponhamos também que até o momento Nogot sempre foi confiável e honesto com Smith. Dado isso, chamemos a conjunção dessas evidências $M$. Assim

\footnotetext{
${ }^{23} \mathrm{O}$ que está em jogo aqui é a sorte verídica, na qual os eventos deste tipo de sorte são, considerando a argumentação de Pritchard (2005), aqueles que obtêm a verdade de maneira acidental, não a alcançando em uma ampla classe de mundos próximos possíveis, onde as condições iniciais relevantes para o evento estão mantidas. Ou seja, a crença estaria sujeita a essa sorte quando existe uma ampla classe de mundos possíveis próximos nos quais a mesma base para a crença resulta numa crença falsa, havendo menos ou mais sorte a depender do quão perto ou distante está o mundo possível que o sujeito forma uma crença falsa a partir da mesma base.
} 
Smith estaria justificado em crer que Nogot, que está em seu escritório, possui um Ford $R$ e, consequentemente, está justificado em acreditar que alguém em seu escritório possui um Ford $(\mathrm{H})$.

Se nesse exemplo considerarmos $R$ falsa, mas, ainda assim, $H$ verdadeira - por exemplo, por Sr. Nogot ter mentido e não ter um Ford, mas alguém no escritório ter -, Smith terá crença verdadeira justificada, mas, tal como nos casos originais de Gettier e em sua perspectiva, não terá conhecimento. Há, todavia, como Richard Feldman sugere, uma maneira de modificarmos esse exemplo tal que não parta de crenças falsas, que a justificativa para $H$ seja verdadeira e que Smith saiba disso

Suppose he deduces from $\mathrm{m}$ its existential generalization:

(n) There is someone in the office who told Smith that he owns a Ford and even showed him a certificate to that effect, and who up till now has always been reliable and honest in his dealings with Smith. (FELDMAN, 1974, p. 69) 2425

Agora, dirá Richard Feldman, $N$ é verdadeira e Smith sabe disso tendo deduzido $N$ de $M$, que é também verdadeira. E, se com base em $N$ Smith acredita em $H$, terá crença verdadeira justificada sem ter partido de crenças falsas. Entretanto, também não há conhecimento, afinal podemos argumentar -, ainda que crenças falsas não tenham estado em jogo, permanece a sorte de $H$ ser verdadeira.

Há ainda outros diferentes exemplos que procuram mostrar essa mesma possibilidade, bem como a independência em relação ao PFJ. Suponhamos, por exemplo, que Smith vê num campo um animal que parece exatamente um cachorro e não inferencialmente forma a crença perceptiva $D$ de que há um cachorro no campo. Consideremos agora que, na verdade, o cachorro é um robô tão perfeito que é impossível distingui-lo de um cão real apenas pela visão. É um robô do tipo de que Smith desconhece a existência e fabricado recentemente, e trata-se de um protótipo para testar a reação do público. Sendo assim, $D$ é falsa. Entretanto, se a poucos metros do cão-robô, no mesmo campo, há um cachorro real oculto da visão de Smith, $D$ permanece verdadeira. Como essa crença é baseada em processos perceptuais comuns, tal como nos casos originais de Gettier, ela seria uma crença verdadeira justificada; todavia, essa crença teria sido

\footnotetext{
24 “Suponha que ele deduza de $\mathrm{M}$ a seguinte generalização existencial:

(n) Há alguém no escritório que disse a Smith que ele é dono de um Ford e até lhe mostrou um certificado para esse efeito, e que até agora sempre foi confiável e honesto em suas relações com Smith." (tradução nossa)

${ }^{25}$ Esse exemplo é apenas um dos quais podemos encontrar na literatura pós-gettierana, tanto anterior como posteriormente a Feldman, e que se pretendem casos de Gettier que não partem de crenças falsas. Muitos deles encontram-se listados por Lycan (2006, p. 154).
} 
diretamente justificada por uma experiência visual e não inferida de qualquer falsidade. Não obstante, como formada a partir da sorte, não seria conhecimento. ${ }^{26}$ É por isso que, até então, adoto o falibilismo e a incompatibilidade com a sorte como pressupostos essenciais dos casos do tipo-Gettier e como razões essenciais para a ilegitimidade desses casos como conhecimento: o fato de serem formados por sorte (que parece trazer, necessariamente, no mínimo a ignorância do sujeito epistêmico sobre a mesma e o que a permite).

Daí também que, ainda que a estrutura dos casos de Gettier proposta por Alexandre Meyer Luz e Linda Zagsbski - que pressupõe que os mesmos envolvem crenças falsas - se aplique aos exemplos originais, e ainda que a explicação do demérito epistemológico dos mesmos em razão da sorte por Linda Zagzebski não seja falsa e destaque o aspecto essencial do demérito, pode haver casos do tipo-Gettier que não envolvam crenças falsas, e o demérito epistemológico, ainda que fundamentalmente atrelado à sorte, pode estar ligado também a crenças falsas e/ou ignorâncias, independentemente do $\mathrm{PFJ}^{27}$. Assim, cito uma compreensão mais geral e aberta, inspirada também em Stephen Hetherington (2018, p. 222), na qual os casos de Gettier incluem um agente ou sujeito epistêmico com uma crença verdadeira falivelmente justificada que não é conhecimento por ter sido formada através de um processo defeituoso, processo em que esse agente ou sujeito não tem conhecimento da circunstância real que se realizou para tornar sua crença verdadeira e/ou tal circunstância não fez parte de sua atividade epistêmica. ${ }^{28}$

Dito isso, podemos melhor entender a finalidade do artigo de Gettier citada inicialmente neste tópico. Em sua crítica, através dos agora chamados casos de Gettier, o filósofo não tenta mostrar que a definição tripartida não é necessária, que toda crença verdadeira justificada não será conhecimento ou que o falibilismo e o PFJ são problemáticos (ainda que a partir de Gettier possamos refletir tudo isso e outras coisas relacionadas); na verdade, Gettier procura nos dizer que, mesmo que uma crença verdadeira justificada qualquer seja conhecimento, apenas atestar a presença desses três elementos não nos garante que é o caso. Em outras palavras, a definição tripartida, mesmo que necessária, seria insuficiente.

\footnotetext{
${ }^{26}$ Exemplo construído a partir de LYCAN (2006, p. 154) e STEUP; ICHIKAWA (2017).

${ }^{27}$ Não estou argumentando que esses autores não reconhecem isso no decorrer de seus textos e em outros trabalhos. Suas citações foram tomadas isoladamente para fins didáticos e reflexivos de diálogo com e exposição do presente texto.

${ }^{28}$ Convém notar que, apesar de ser em grande medida ponto pacífico a interpretação de os casos de Gettier não serem conhecimento devido ao fato de crença verdadeira justificada ter sido alcançada por acidente, parece-me controverso o que teria causado esse acidente, isto é, o que aconteceu de errado e faltou para que o resultado fosse conhecimento. Essa controvérsia se revela quando percebemos que diferentes tentativas de solução pressupõem diferentemente o problema a ser solucionado e sua solução. Para uma introdução às respostas ao problema de Gettier, $c f$. HETHERINGTON (2005) e STEUP; ICHIKAEA (2017).
} 
Tal conclusão pode nos levar a perguntar, razoavelmente, o seguinte: por que a conclusão generalizada de que a crença verdadeira justificada não é suficiente para o conhecimento, se Gettier nos mostrou apenas dois casos nos quais isso ocorre, sendo inclusive casos marcados pela estranheza, que parecerem pouco frequentes ou até mesmo raros? Não haveria outros casos nos quais a definição tripartida é suficiente?

Por um lado, a definição tripartida nos diz que qualquer atual ou possível caso de conhecimento é uma atual ou possível instância de crença verdadeira justificada, e que qualquer atual ou possível instância de crença verdadeira justificada é conhecimento. Assim, a definição tripartida não é suficiente se há ao menos uma atual ou possível situação em há crença verdadeira justificada, mas não conhecimento, e vice-versa. Por outro lado, a epistemologia analítica tradicional deseja entender o conhecimento em todas as suas instâncias ou manifestações reais ou possíveis, ou seja, de forma universalmente aplicável. Aceitando a conclusão de Gettier, há ao menos dois casos nos quais a definição tripartida não é suficiente e, consequentemente, pode haver a possibilidade de ela não o ser em outros casos. Essa conclusão desmonta e mostra a insatisfação da pretensão de universalidade dessa definição por parte dessa epistemologia. $^{29}$

\section{CONSIDERAÇÕES FINAIS}

Nas palavras de Alexandre Meyer Luz, os resultados da crítica de Gettier

[...] vão, pois, consistir em ataques mortais à antiga definição tripartite de conhecimento proposicional, acertando-a no coração: na noção-chave de justificação. Gettier nos mostrou que, mesmo que estejamos justificados, que mesmo que estejamos naquilo que consideraríamos inicialmente uma excelente posição para saber, dispondo de excelentes evidências, estaremos sujeitos a uma conjunção de fatores externos a nós e que nos afastam daquela situação que desejamos, a da verdade atingida com mérito (como vimos, os casos de Gettier forneciam, exatamente, casos em que a verdade era atingida, mas sem mérito). A questão, pois, está mais além da mera suposição de que dispor de justificação para uma crença talvez não seja algo frequentemente realizável, dadas nossas limitações. Gettier merece os méritos por ter apontado para algo de novo na história da epistemologia: a busca pela evidência que garanta a verdade é, de fato, em vão. Podemos estar, como vimos, justificados e, mesmo assim, atingirmos a verdade sem mérito algum (não possuindo, pois, conhecimento). (LUZ, 2013, p. 30)

${ }^{29} C f$. HETHERINGTON (2005). 
Tamanho é seu convencimento de Gettier estar certo que alerta que falarmos da crítica de Gettier se refere não apenas ao ataque histórico desse autor à definição tripartida, mas a um desafio a qualquer tentativa de definir o que é o conhecimento proposicional, desafio esse que se chama problema de Gettier e que as tentativas de definição do conhecimento precisarão dissolver, não sucumbindo a ele.

O próprio Gettier (1963, p. 121) alega em seu artigo que sua crítica não se aplica somente à formulação da definição tripartida apresentada até então, mas também, com as devidas modificações, a outras formulações, como a de Chisholm ou Ayer, ou seja, respectivamente, "S sabe $\mathrm{P}$ se e somente se (i) S aceita que $\mathrm{P}$, (ii) $\mathrm{S}$ tem provas adequadas para $\mathrm{P}$, e (iii) $\mathrm{P}$ é verdadeira", ou "S sabe que $\mathrm{P}$ se e somente se (i) P é verdadeira, (ii) S está seguro de que P é verdadeira, e (iii) S tem o direito de estar seguro de que P é verdadeira”.

O problema de Gettier, no entanto, não se limita apenas ao que resulta imediatamente de seu artigo e de suas finalidades. A partir do momento em que são recebidas e discutidas pela comunidade filosófica mundial, percebe-se, especialmente na tentativa de dissolvê-las, que as implicações e complexidades dessa crítica vão além das intenções postas por Gettier. Essas novas complicações se agregam à compreensão do problema de Gettier, tornando o desafio mais poderoso, de modo que curiosamente já se fala também em problema do problema de Gettier $^{30}$ como uma referência à dificuldade duradoura e recorrente de solucioná-lo.

Desde então a definição tripartida, a crítica de Gettier e a literatura gerada por essa crítica $^{31}$ têm sido alvos de discussões e controvérsias, firmando-se como problemas a serem necessariamente solucionados tendo em vista qualquer pretensão atual de definirmos analiticamente o conceito de conhecimento. Nesse contexto, justifica-se não somente o estudo e discussão em geral sobre essa definição, a crítica de Gettier e a literatura gerada por ela, como especificamente sobre o quanto a definição se sustenta e a crítica se aplica, e quais seriam as implicações de aceitarmos ou não tal crítica e a insuficiência da definição tripartida. Especialmente, cabe a questão filosófica por excelência, posta de início: o que é conhecimento?

\footnotetext{
${ }^{30}$ Cf. LYCAN (2006, p. 148-168) e HETHERINGTON (2018, p. 218).

${ }^{31}$ Para Giovanni Rolla, em uma epistemologia pós-Gettier cinco foram os tipos de reação aos seus contraexemplos, listado a partir de uma analogia política. Para mais informações ver ROLLA (2018, p. 50).
} 


\section{REFERÊNCIAS BIBLIOGRÁFICAS}

AUDI, Robert. Epistemology: a contemporary introduction to the theory of knowledge, n. 2. USA: Routledge, 2003.

BERNECKER, Sven; DRETSKE, Fred (Eds.). Knowledge: readings in contemporary epistemology, n. 3. New York: Oxford University Press, 2005.

BERNECKER, Sven; PRITCHARD, Duncan (Eds.). The Routledge companion to epistemology. United Kingdom: Routledge, 2011.

BONJOUR, Laurence. Epistemology: classic problems and contemporary responses, n. 2. USA: Rowman \& Littlefield Publishers, 2009.

DANCY, Jonathan; SOSA, Ernest; STEUP, Matthias (Eds.). A companion to epistemology, n. 2. United Kingdom: Wiley-Blackwell, 2010.

DUNCAN, Pritchard. Epistemic luck. United Kingdom: Oxford University Press, 2005.

DUTRA, Luiz Henrique de Araujo. Introdução à epistemologia. São Paulo: Editora UNESP, 2010.

FELDMAN, Richard. An alleged defect in Gettier counterexamples. Australasian journal of philosophy, 52:1, 68-69, 1974.

GETTIER, Edmund. É a crença verdadeira justificada conhecimento? Trad. Célia Teixeira com revisão de W. J. Silva Filho. Investigações filosóficas. Disponível em: <http://www.investigacoesfilosoficas.com/wp-content/uploads/Gettier-1963-E_-a-crenc_averdadeira-justificada-conhecimento.pdf>. Acessado em 28 de agosto de 2019. . Is justified true belief knowledge? Analysis, v. 23, n. 6, p. 121-123, 1963.

HETHERINGTON, Stephen. Gettier Problems. Internet encyclopedia of philosophy. Disponível em: <https://www.iep.utm.edu/gettier/>. Acessado em 22 de agosto de 2019.

. Knowledge. Internet encyclopedia of philosophy. Disponível em: <https://www.iep.utm.edu/knowledg>. Acessado em 21 de agosto de 2019.

. The Gettier problem. United Kingdom: Cambridge University Press, 2018.

ICHIKAWA, Jonathan Jenkins; STEUP, Matthias. The analysis of knowledge. Stanford encyclopedia of philosophy. Disponível em: <https://plato.stanford.edu/entries/knowledgeanalysis/>. Acessado em 22 de agosto de 2019.

LUZ, Alexandre Meyer. Conhecimento e justificação: problemas de epistemologia contemporânea. Pelotas: NEPFIl online, 2013. 
LYCAN, William G. On the Gettier problem. In: HETHERINGTON, Stephen (Ed.). Epistemology futures. New York: Oxford University Press, 2006.

MORTON, Adam. A guide through the theory of knowledge, n. 3. USA: Blackwell Publishing, 2003.

O'BRIEN, Dan. Introdução à teoria do conhecimento. Trad. Pedro Gaspar. Lisboa: Gradiva, 2013.

ROLLA, Giovanni. Epistemologia: uma introdução elementar. Porto Alegre: Editora Fi, 2018.

PLATÃO. Teeteto. Trad. Adriana Manuela Nogueira e Marcelo Boeri. Lisboa: Fundação Calouste Gulbenkian, 2010.

TRUNCELLITO, David A. Epistemology. Internet encyclopedia of philosophy. Disponível em: 〈https://www.iep.utm.edu/epistemo/>. Acessado em 22 de agosto de 2019.

WILLIAMS, Michael. Problems of knowledge: a critical introduction to epistemology. USA: Oxford University Press, 2001.

ZAGZEBSKI, Linda Trinkaus. "The Inescapability of Gettier Problems". In: The Philosophical Quartely. Vol. 44, No 174, jan. 1994, p. 65-73. What is knowledge? In: GRECO, John; SOSA, Ernest (Eds.). The Blackwell guide to epistemology. Oxford: Blackwell, 1999. p. 92-116.

. The lesson of Gettier. In: BORGES, Rodrigo; ALMEIDA, Claudio de; KLEIN, Peter D. (Eds.). Explaining knowledge: new essays on the Gettier problem. United Kingdom: Oxford, 2017. 